\title{
DISSEMINAÇÃO DE VALORES ÉTICOS NO ENSINO DO CUIDAR EM ENFERMAGEM: ESTUDO FENOMENOLÓGICO ${ }^{1}$
}

\author{
Alan Dionizio Carneiro², Solange Fátima Geraldo da Costa ${ }^{3}$, Marconi José Pimentel Pequeno ${ }^{4}$
}

\footnotetext{
${ }^{1}$ Recorte da dissertação - Valores éticos no ensino do cuidar em Enfermagem: um estudo fenomenológico a partir de Max Scheler, Programa de Pós-Graduação em Enfermagem da Universidade Federal da Paraíba, 2008.

2 Doutorando do Programa Integrado de Doutorado em Filosofia das Universidades Federais da Paraíba, Pernambuco e Natal (PIDFIL/UFPB, UFPE, UFRN). Professor do Curso de Bacharelado em Enfermagem da Universidade Federal de Campina Grande. Paraíba, Brasil. E-mail: dionizioccs@hotmail.com

${ }^{3}$ Doutora em Enfermagem. Professora do Programa de Pós-Graduação em Enfermagem da UFPB. Orientadora da dissertação. Paraíba, Brasil. E-mail: solangefgc@gmail.com

${ }^{4}$ Doutor em Filosofia. Professor do PIDFIL/UFPB, UFPE, UFRN. Paraíba, Brasil. E-mail: marconip@bol.com.br
}

RESUMO: Este estudo teve como objetivo investigar como professores de Enfermagem disseminam valores éticos no ensino do cuidar em enfermagem a partir do referencial axiológico de Max Scheler. Trata-se de uma pesquisa fenomenológica realizada com a participação de 12 professores de enfermagem da Universidade Federal da Paraíba. Os dados foram coletados por meio da técnica de entrevista no período de agosto a setembro de 2008. A análise do material empírico efetivou-se mediante uma abordagem qualitativa, à luz da fenomenologia Scheleriana. Deste modo, foi possível compreender que os educadores fazem uso de uma comunicação diretiva, usando mandados pedagógicos (conselhos, recomendações, deliberações morais, entre outros) para disseminar valores éticos direcionados a prática do cuidar. Logo, os valores éticos não podem ser ensinados apenas teoricamente, precisam estar respaldados em uma experiência real ou imaginária e ser uma descoberta do mundo do cuidar para ter sua eficácia no processo ensino- aprendizagem.

DESCRITORES: Cuidados de Enfermagem. Ética. Educação em Enfermagem. Docente de Enfermagem. Filosofia.

\section{SPREADING ETHICAL VALUES IN TEACHING NURSING CARE: A PHENOMENOLOGICAL STUDY}

\begin{abstract}
The objective of this study was to investigate how nursing professors disseminate ethical values in teaching nursing care based on Max Scheler's axiological reference. This investigation consisted of a phenomenological research developed with the participation of 12 nursing professors from the Federal University of Paraíba, Brazil. The data were collected through a semi-structured interview given between August and September of 2008. The empirical data were analyzed with a qualitative approach, using Max Scheler's phenomenology. Thus, it was possible to understand that nursing professors use directive communication, using pedagogical guidelines (advice, recommendations, moral deliberations, among others) to spread ethical values directed to care practices. Thus, ethical values may not be taught merely theoretically, they need to be based on real or imaginary experience and be a discovery of the world of care in order to have its effectiveness in the teaching-learning process.
\end{abstract}

DESCRIPTORS: Nursing care. Ethics. Education. Faculty, Nursing. Philosophy.

\section{DIFUSIÓN DE VALORES ÉTICOS EN LA ENSEÑANZA DEL CUIDADO EN ENFERMERÍA: UN ESTUDIO FENOMENOLÓGICO}

RESUMEN: El objetivo de este estudio fue investigar cómo los docentes de enfermería difunden los valores éticos en la enseñanza del cuidado en enfermería a partir del marco conceptual axiológico de Max Sheler. Es una investigación fenomenológica que fue realizada con la participación de 12 docentes de enfermería de la Universidad Federal de la Paraiba. Los datos se recolectaron mediante entrevistas realizadas de agosto a septiembre de 2008. El análisis del material empírico se llevó a cabo mediante un enfoque cualitativo según la fenomenología Scheleriana. Así, fue posible comprender que los educadores emplean una comunicación directa utilizando las directrices pedagógicas (consejos, recomendaciones y deliberaciones morales, entre otras) para la transmisión de los valores éticos para la práctica del cuidado. Los valores éticos no pueden ser enseñados sólo en teoría, tienen que basarse en una experiencia real o imaginaria y ser un descubrimiento del mundo del cuidado para ejercer su función en el proceso de enseñanza y aprendizaje.

DESCRIPTORES: Cuidar en enfermería. Ética. Educación. Docente de Enfermería. Filosofía. 


\section{INTRODUÇÃO}

A Enfermagem é uma ciência e uma arte em construção, revisitando e inovando suas bases filosóficas e epistemológicas, por meio de teorias e modelos conceituais destinados a oferecer ações seguras para o desenvolvimento do ensino e das atividades dos profissionais comprometidos com o outro em sua condição e em sua essência. É oportuno compreender que, neste contexto, a Enfermagem arrogou-se, como objeto e finalidade de sua ciência, o cuidado.

Esse cuidado envolve habilidades do profissional de enfermagem, em especial, do enfermeiro, tais como, reconhecer valores pessoais, instilar fé e esperança, cultivar a sensibilidade, estabelecer uma relação de ajuda-confiança que permita a expressão de sentimentos, sistematizar um processo de cuidar científico criativo, permitir ao outro ensinar/aprender a ser cuidado, assegurar um ambiente confortável onde o outro se sinta apoiado e protegido, como também, assistir ao outro em necessidades biológicas e até mesmo espirituais. ${ }^{1}$

Nesse sentido, o cuidado em enfermagem reivindica mais que um elemento objetivo, teóricocientífico, já que ele exige a percepção de um componente axiológico-intersubjetivo capaz de ajudar o cuidador a estabelecer uma ocasião de cuidado empático e autêntico centrado no outro.

Esta compreensão axiológica sobre o cuidar em enfermagem torna-se ainda mais evidente uma vez que o ensino centrado em argumentos morais encontra-se contemplado em currículos acadêmicos, abordagens pedagógicas, procedimentos metodológicos de ensino, a fim de suscitar consciência e sensibilidade diante do mundo. ${ }^{2}$ Ademais, o ensino em enfermagem notadamente em sua dimensão moral, deve considerar que o aprendizado do aspirante a enfermeiro percorreu diversos palcos dentro da família, comunidade, escola e sociedade, cuja finalidade consistiu em prepará-lo para um comportamento responsável.

Assim, o mundo moral da pessoa, em especial, do estudante, é também portador de uma individualidade que determina, em grande parte, seu conhecer e seu querer na enfermagem. $\mathrm{O}$ professor aparece como um agente importante na formação do aluno, bem como do ethos do cuidado que une razão e sensibilidade (pathos). Ele deve ser promotor de uma enfermagem humanística quanto aos seus princípios e humanizada quando se referir à prática assistencial. É essa relação professor-estudante que subsidiará o olhar do futuro profissional no que concerne ao cuidado.
Convém mencionar que os valores devem orientar as ações criadoras do homem (imaginação e inteligência), servindo como indicadores, em cada caso, do desenvolvimento histórico da humanidade. ${ }^{3}$ Nessa perspectiva, os valores constituintes do cuidar incidem sobre a experiência individual tanto do professor de enfermagem como do estudante e, sobre a evolução histórica daquilo que compreendemos por cuidar. Portanto, a ética pautada na reflexão sobre valores, é um guia para o surgimento de uma nova prática de enfermagem, mais sensível e, quiçá, menos racional. Contemplando o ensino da ética no cuidado em enfermagem, compreende-se que é necessário aprofundar o conhecimento sobre as teorias dos valores para se poder encontrar valores e deveres que nos conduzam a uma maior responsabilidade em relação ao outro.

Desta forma, a fim de elucidar aos professores, estudantes e cuidadores de enfermagem a importância e a necessidade da ética para a formação profissional e para o cotidiano de cuidar em enfermagem, buscamos realizar um trabalho envolvendo as temáticas da ética, do ensino e do cuidar em enfermagem, por meio do referencial filosófico de Max Scheler, que resgata idéias concernentes a sentimentos, valores e à importância do outro e da comunicação para o processo de formação ética da pessoa, dando especial significado à experiência vivida e à sentimentalidade a ela atrelada.

Com base nesta assertiva, pode-se mencionar que o pensamento de Max Scheler, alicerçado na fenomenologia e na experiência vivida, permite uma reflexão adequada sobre os fundamentos axiológicos do cuidar em enfermagem e seu ensino. O referido filósofo dedica parte de seu trabalho à possibilidade de fundamentação de uma ética material pautada em valores contidos na experiência, propondo uma hierarquia de valores e caminho de ascese no mundo dos valores, através do amor e do perceber sentimental.

Diante das considerações apresentadas, este estudo teve como objetivo investigar como professores de enfermagem disseminam valores éticos no ensino do cuidar em enfermagem a partir do referencial axiológico de Max Scheler.

\section{CONSIDERAÇÕES SOBRE A TEORIA DOS VALORES DE MAX SCHELER}

A teoria dos valores de Max Scheler, procura responder a uma necessidade ética mostrando como firmá-la na materialidade da experiência, de 
modo a não restringir comportamentos à mera observância de normas gerais prescritas por qualquer instituição ou autarquia da enfermagem, que nem sempre respondem aos dilemas específicos vividos por acadêmicos e enfermeiros em seu cotidiano.

Alicerçado no pensamento de Scheler, podese dizer algo relevante para as práticas profissional e docente em enfermagem que consiste na concepção de que o estudo da ética e do cuidar também se vincula à materialidade e ao sentimento, na medida em que toda ética deveria "[...] aperfeiçoarse no descobrimento das leis do amor e do ódio, que excedem as leis do preferir e as que existem entre as qualidades dos valores correspondentes no que diz respeito a seu grau de absolutividade, aprioridade e primordialidade" . $^{4: 365}$

$\mathrm{O}$ valor requer sempre uma experiência ou uma vivência, posto que a reivindica para que seja possível, nessa interação, fazer emergir o sujeito cognoscente, capaz de sentir, de visualizar, de reconhecer e de apreender estes valores. Desse modo, não é possível uma definição do que sejam valores, mas uma clarificação. Atrelar o valor a uma vivência humana remete à compreensão de que o componente de valoração é intrínseco ao ser humano, permeando sua existência, ressaltando que os valores não são captados pelo intelecto, nem constituem fins determinados pela vontade, mas são apreendidos pela pessoa por meio de emoções e sentimentos. ${ }^{5}$

Com efeito as atitudes de conhecer e querer lhe são inatas não sendo, pois, concebível a existência de uma pessoa humana que não valore ou não emita juízos de valor. Com base nesse aspecto, Scheler apresenta quatro axiomas anteriormente formulados pelo filósofo Francis Brentano, quais sejam: a existência de um valor positivo é, em si mesmo, um valor positivo; a existência de um valor negativo é, em si mesmo, um valor negativo; a inexistência de um valor positivo é, em si mesmo, um valor negativo; a inexistência de um valor negativo é, em si mesmo, um valor positivo. ${ }^{5}$

Assim, a relação entre sentimento (amor) e valor pode ser melhor compreendida pela seguinte sentença: "Um ato de vontade supõe um amor que lhe precede e lhe imprime direção e conteúdo. É, portanto, sempre o amor que nos desperta para conhecer e querer [...]".$: 45$ Com base nesse entendimento, tal estrutura anímica faz da pessoa sempre um "ser-aberto-á", e pelo amor, um ens intentionale no mundo, capaz de apreender valores, preferir, preterir, inclusive de dizer não ao mundo, definindo tudo isso por meio de suas experiências e vi- vências. O homem, deste modo, torna-se um asceta da vida, aquele que não permanece preso a uma mera realidade ou aos seus instintos. Desta forma, a emotividade é o instrumento por meio do qual o valor, enquanto instância constituinte da moral, pode ser captado pela pessoa na experiência. ${ }^{7}$

Nesse sentido, o aperfeiçoamento moral da sociedade decorre da maneira como as pessoas constroem sua concepção de mundo e sua forma de sentir e valorar a realidade ao longo de sua história, expressando, em cada ação, sua individualidade, seu modo-de-ser e suas convicções. Segundo Scheler, os valores se articulam entre o indivíduo e o social a partir de uma relação sentimental, afetiva. ${ }^{8}$

Nos termos desse personalismo, a pessoa é antes um ens amans, que reivindica alguns elementos para a sua realização, quais sejam: sair do individualismo (egocentrismo), transcendendo a si mesmo; procurar compreender a si com os olhos do outro, não se superestimar a ponto de tornar-se medida autoritária de verdade para com o outro, exercitar atitudes de acolhimento e recolhimento; assumir a condição de pessoa finita e relacional; e, ser fiel a estes postulados, pois amizade, amor e dedicação aperfeiçoam-se, planificam-se na continuidade de uma prática. ${ }^{9} \mathrm{~A}$ participação no mundo do outro é elemento e sentido de existência da pessoa, é fundamento e meta do amor e caminho para a solidariedade.

\section{CONSIDERAÇÕES METODOLÓGICAS}

O estudo proposto consiste numa pesquisa de campo de natureza fenomenológica com abordagem qualitativa, tendo como escopo referencial a cosmovisão proposta por Max Scheler, a qual procura elucidar o cerne do fenômeno tal como ele se nos mostra, diante daquilo que o sujeito experiência, de modo que uma compreensão do fenômeno deve ter " $[. .$.$] em primeiro lugar e como$ característica fundamental, um contato vivencial com o próprio mundo, ou seja, com os objetos em questão. Esse contato deve ser vivo, intenso e imediato no mais alto grau com os objetos tal como se oferecem de forma imediata na vivência, ou seja, no ato da vivência, e tal como eles mesmos existem nesse ato e somente nele" ${ }^{10: 85}$

A pesquisa fenomenológica busca descrever o significado da experiência humana, a partir do fenômeno vivido. Convém recordar o princípio basilar de que o estudo fenomenológico é uma volta às coisas mesmas. ${ }^{11}$ 
Participaram dessa pesquisa 12 professores, lotados nos Departamentos de Enfermagem do Centro de Ciências da Saúde da Universidade Federal da Paraíba (CCS/UFPB). Destes participantes, sete possuíam titulação de Mestre, quatro de Doutor e um de Pós-doutor. No que tange aos critérios de inclusão e exclusão dos participantes para esta investigação, foram eleitos os seguintes itens: exercer atividades docentes há pelo menos dois anos; estar lecionando disciplinas práticas de enfermagem; ter disponibilidade e aceitar participar do estudo proposto.

É oportuno esclarecer que, quanto ao número de participantes nesta modalidade de investigação, o importante não é a quantidade de indivíduos integrantes do estudo, mas, sim, a significância e a intensidade com que o fenômeno ocorre. ${ }^{12}$ Isto implica dizer que esse tipo de pesquisa não se alicerça no critério numérico para sua representatividade, mas na possibilidade de compreensão do fenômeno investigado em suas diversas dimensões, a partir da apreensão dos dados coletados. ${ }^{13}$

No que concerne à coleta de informações, esta ocorreu no período de agosto a setembro de 2008. A fim de viabilizar o contato com os professores, o pesquisador agendava um encontro em que, por ocasião da entrevista, procedia da seguinte forma: fazia-se uma breve explanação do estudo e sua finalidade e apresentava o Termo de Consentimento Livre e Esclarecido (TCLE). Este deixava claro o respeito à autonomia do professor em optar por participar ou não da investigação proposta. Após a leitura do referido termo, convidávamos aqueles que aceitassem a assinar o termo conjuntamente com o pesquisador concretizando sua anuência.

No que tange à escolha da técnica de entrevista, utilizou-se um formulário contendo questões pertinentes aos objetivos do estudo, ressalvando que, para o registro dos depoimentos, foi utilizado o sistema de gravação de áudio, já previamente comunicado aos professores durante os esclarecimentos iniciais. Além disso, o pesquisador teve o zelo de deixar o gravador de modo inaparente ao participante do estudo, para que o objeto, por seu simbolismo, não viesse a inibi-lo.

No transcorrer do trabalho, foram considerados os aspectos éticos dispostos na Resolução No 196/96 do Conselho Nacional de Saúde, referente à pesquisa envolvendo seres humanos no cenário brasileiro, principalmente no que diz respeito ao TCLE do participante. Da mesma forma garantiu-se seu anonimato e o sigilo dos dados confidenciais, tendo sido esta pesquisa aprovada pelo Comitê de Ética em Pesquisa do CCS/UFPB sob o protocolo $\mathrm{N}^{\mathrm{0}} 0347$ de 2008.

Retomando a trajetória metodológica, a análise das informações efetivou-se mediante uma abordagem qualitativa, à luz do referencial filosófico proposto por Max Scheler. Para a demonstração da tessitura auto-axiológica do fenômeno investigado levou-se em conta a redução fenomenológica, através das etapas operacionais indicadas por Moustakas,$^{14}$ descritas sequencialmente a seguir.

- Usando uma aproximação fenomenológica: nesta etapa, o pesquisador procurou ouvir de maneira atenta e detalhada cada entrevista, buscando uma melhor compreensão do fenômeno investigado a partir da fala dos depoentes.

- Transcrição textual: este momento foi marcado pela necessidade de autenticação do depoimento como um retrato fidedigno daquilo que o participante compreendia como sua vivência. Assim, realizada a transcrição do relato, o pesquisador contactou os participantes novamente e lhes entregou uma cópia transcrita do relato acrescido de um CD-room contendo o áudio da entrevista na íntegra para que o professor pudesse confirmar sua fala, reafirmar seu consentimento e interesse em participar do estudo e informar alguma falha que pudesse estar presente na transcrição. Após a confirmação e a nova autorização pelo participante da investigação, o pesquisador deu início à etapa seguinte da análise.

- Revelação das essências do fenômeno oriundo da experiência: este ponto consistiu em visualizar a beleza de cada discurso individual e suas nuanças. Primeiramente, procurou-se fazer uma leitura minuciosa dos relatos visando à essência de cada discurso. De maneira didática, esta etapa envolveu, seleção de fragmentos relevantes para descrição da experiência, contempladas em cada depoimento dos participantes inseridos no estudo, atribuição de um tema correspondente; por meio da variação imaginária, buscou-se apreender o tipo de relação que cada faceta possuía para com o fenômeno. Finalizando este processo de transcrição textual e revelação de essências individuais, repetiu-se este processo de busca por essências e construção de facetas da experiência em todos os depoimentos do estudo.

- Construção das categorias da descrição fenomenológica: terminada a busca pelas essências e respectivas conexões presentes às experiências individuais dos professores participantes do estudo, 
o pesquisador procurou realizar um agrupamento a partir das facetas identificadas nos depoimentos dos envolvidos na pesquisa. Desse modo, integrou-se todas as estruturas individuais em uma descrição universal de experiências do fenômeno vivido, representadas por um enunciado comum que chamamos de categoria, isto é, a essência do fenômeno investigado. Esta etapa compreende na linguagem scheleriana, o chamado Circulus in definiendo, ou seja, o olhar constante do pesquisador sobre o que seja a essência do fenômeno.

A etapa final da análise compreendeu a Discussão Fenomenológica a partir do pensamento de Max Scheler. Nesta etapa, o pesquisador, cônscio de que só se pode afirmar que essa experiência é autêntica apenas para esse grupo de professores, procurou discutir o fenômeno vivido a partir das essências e suas conexões formais com a ajuda do referencial filosófico e da literatura pertinente ao objeto de estudo, não podendo o investigador tomar posicionamentos arbitrários em relação ao fenômeno vivido. Tal etapa corresponde ao Circulus in demonstrando, o qual consiste na constante descrição e discussão do fenômeno. ${ }^{4,15}$

\section{CIRCULUS IN DEMONSTRANDO: DIS- CUSSÃO FENOMENOLÓGICA}

O professor de enfermagem que, em seu ateneu, é cientista por formação, cuidador por natureza e desbravador da arte de ensinar e do mundo de valores. Este experimenta um dilema cotidiano acerca de como trabalhar as especificidades da teoria e da prática, sem sobrepujar um em prejuízo do outro e comunicá-las aos aspirantes à profissão de enfermagem, assegurando, ao mesmo tempo, a promoção de uma formação ética.

Nesse sentido, passamos à discussão fenomenológica direcionada especificamente para a categoria, a qual se reporta à comunicação diretiva entre professor e estudante, evidenciada a partir da indagação feita aos participantes do estudo sobre como, em suas vivências, os mesmos procuram disseminar valores éticos no ensino teórico e prático do cuidar em enfermagem. Tal categoria está representada, com base na linguagem scheleriana, na sentença, ou melhor, no caput do tópico a seguir.

\section{Utilizando mandados pedagógicos para sen- sibilizar o estudante}

Toda educação possui um componente valorativo positivo ou negativo, seja no âmbito pedagógico (didático, formativo) ou moral, pois a arte de ensinar pressupõe valores e estratégias, em especial por parte dos professores que, no seu convívio cotidiano com o estudante, buscam alertá-lo sobre a relevância e aplicabilidade de determinados saberes que, no caso da Enfermagem, se fundamenta em postulados científicos.

Neste contexto, dentre as técnicas de ensino utilizadas pelos professores encontra-se o uso de mandados, isto é, instruções predicativas para uma ação moral, os quais Scheler diferencia em mandados autênticos e mandados pedagógicos ou educativos (pseudomandados), que nada mais são do que as formas indicativas de conteúdos e deveres, tais como, a ordem, o pseudomandado, o conselho, a deliberação moral ou consulta, a recomendação e a proposta. ${ }^{4}$

Com intuito de clarear tais distinções, oferecemos algumas exemplificações. Ordem: tu fazes isto. Conselho: o melhor para ti é que faças isto, e eu quero que tu faças o melhor para ti. Consulta: se eu fosse tu, faria isso e não aquilo. Recomendação: eu penso que seria necessário tu fazeres isto. Proposta: acho que tu deverias proceder desta forma para realizar o que deve.

Convém apresentar as distinções destas modalidades de mandados para uma melhor compreensão dos depoimentos dos participantes desta investigação. A ordem é unidiretiva, ou seja, quem manda transmite sua vontade e um dever-ser geral, sem preocupar-se sobre a participação do outro nesta, ou mesmo na sua liberdade de decisão, em outros termos, implica ao outro um dever que lhe tolhe a liberdade/autonomia. O pseudomandado pedagógico comunica um dever-ser ideal específico para um indivíduo, mas salvaguarda-lhe o poder de escolha e decisão. O conselho não possui características normativas, pois sua expressão volitiva recai sobre o indivíduo e parte não somente do que se considera dever ideal para o outro, como também do que realmente se quer para ele. ${ }^{7}$

Com efeito, a deliberação moral é uma ajuda para o outro reconhecer o dever-ser e o não deverser, evitando o apelo do simples querer; a recomendação, por sua vez, figura na comunicação daquilo que se pensa como dever do outro, sem agregá-la a uma vontade; a proposta, com traços peculiares, não se direciona para o dever-ser propriamente dito, mas para o modo de sua realização. ${ }^{7}$

Destarte, os preceitos e orientações educativas procuram o livre melhoramento de cada pessoa, estudante, sendo, portanto, proposições que recaem, em geral, sobre o título de conselho. 
Assim, os mandados pedagógicos podem ser visualizados nos relatos como uma estratégia de comunicação de conteúdos e experiências, conforme destacamos nos trechos abaixo.

Eu disse: "Vamos tentar hoje, de repente você consegue". E disse para ela que, assim, ela tinha que enfrentar o medo dela e dar confiança a ela [...]. Ela tinha que despertar que aquilo para ela era importante (Depoimento 1).

Eu sempre explico para que eles possam refletir, ter esse senso crítico, [...]. A importância da gente conduzir à humanização (Depoimento 11).

Partindo desses mandados pedagógicos expostos pelos professores dessa investigação, procura-se, neste estudo, evitar uma classificação desses relatos quanto ao tipo de mandado, posto que, a depender da maneira como foram expressos, no diálogo vivo com o estudante, podem sofrer variações.

Por outro lado, as falas dos depoentes enfocam o uso de mandados pedagógicos como uma incitação ao exercício de virtudes e à propositura de intenções aos estudantes, requerendo, como tarefa do educador, despertar as potencialidades dos mesmos (consciência de poder), de modo que estes possam cumprir determinadas obrigações ensinadas não pelo simples condicionamento, mas por meio de uma consciência reflexiva reconhecendo o valor ou o dever-ser ideal, presentes em seu cotidiano com vistas ao cuidar.

No tocante ao princípio de diálogo mediante o uso cotidiano e sistemático de mandados ou recursos pedagógicos, esclarece-se que o fundamento e objetivo do professor que, neste caso, é o de enfermagem, não tem como foco chamar a atenção do estudante ou forçá-lo a assimilar conhecimentos de uma disciplina ou ciência, assim como a consequência de certos atos, mas antes é tarefa do tutor apresentar ao estudante valores que, por sua inexperiência e intempestividade, dificilmente os descobriria ou conheceria sozinha.

A utilização de mandados pedagógicos evidencia uma vontade dos professores e acrescida de uma expectativa de abertura do estudante, de esperança em repassarem tudo aquilo que consideram relevante para o aprendizado. Não obstante, o uso deste recurso comunicativo nem sempre está congruente com os interesses do estudante; além disso, por mais eficaz que seja o processo de ensino-aprendizagem, ele não incide nem conhece diretamente, qual seja sua disposição de ânimo, desenvolvendo no professor uma frustração como descreve um dos depoentes.
[...] a gente vem trabalhando algumas questões, [...] oficinas, porque o que eu percebi foi que você simplesmente [...] estar ditando condutas, estar dizendo como os alunos devem se comportar, ou não, devem agir, ou não, eu não consegui ver uma boa receptividade, nem uma boa resposta nisso (Depoimento 7).

Faz-se mister trazer o posicionamento de que educandos motivados (cuja disposição de ânimo se coaduna com o ideal proposto pelos professores), é uma expectativa constante do professor e um medidor preliminar da avidez dos estudantes com relação ao conteúdo da disciplina. Todavia, a práxis do ensino é uma difícil arte, uma vez que muitos estudantes são pouco desejosos de aprender e menos ainda de trabalhar, ressaltando-se que muitos não possuem perspectivas, desejos, são carentes de sonhos. Soma-se a estas dificuldades, o fato de os professores trabalharem com classes homogêneas em que os estudantes são submetidos a uma escolarização de massa, incapaz de atentar para a individualidade e capacidade crítica dos mesmos. ${ }^{16}$

Scheler considera que os educadores "[...] hão de fato ressaltar acertadamente que se há de tender a aumentar nos alunos a consciência de poder e submete-la, por assim dizer, a um cultivo independente. Às vezes dormem no homem muitas forças que não chegam nunca à sua realização porque aquele não possui a exata consciência do poder, a consciência do poderio de sua vontade" . 4:330

Este contexto comunicativo, por vezes árduo, pode ocasionar o pessimismo e o comodismo de professores que passariam a transferir a responsabilidade integral do aprender para o estudante. Um ponto que merece reflexão é o poder de legislar e julgar dentro da relação de ensino, aspecto este conhecido como poder disciplinar do professor. Este aspecto, se não for balizado por virtudes como prudência e respeito, pode ser prejudicial aos alunos. ${ }^{17}$

A Enfermagem, por exemplo, enquanto profissão da área de saúde, é marcada pela obstinação terapêutica que erige a falsa idéia de profissionais super-humanos, isentos da possibilidade de errar. O professor, com isso, pode exceder em seu comportamento, ou seja, em sua autoridade, transformando-se em um ditador na visão do aluno. Esta falsa idéia e comportamento, ainda podem conduzir o estudante ao medo da repressão, de falhar, gerando um condicionamento capaz de fazê-lo seguir rigorosamente todas as instruções e, sob os olhares de seus tutores, arrefece sua capacidade de criticidade. $\mathrm{O}$ ensino passa a ser um adestramento. $^{17}$ 
Vale ressaltar, que essas idéias de comodidade, de pessimismo e de negatividade no processo de ensino não foi mencionado pelos entrevistados, sendo destacado, por estes, apenas que uma educação ditatorial (que dita conteúdos e comportamentos) não é benquista pelos estudantes. Todavia, a flexibilidade didática da arte de ensinar, uma vez que os professores são impulsionados a desbravar e a empregar novos recursos suplementares que possibilitem o diálogo e a vivência do estudante, através de uma experiência vivida ou idealizada, a exemplo de uma oficina, um procedimento técnico, como um banho em um paciente, de modo que, no intercâmbio de saberes, os professores sejam capazes de ofertar seus valores e conhecimentos.

Neste sentido, os professores de enfermagem partícipes desse trabalho revelam que, a partir da experiência, se dá a diferenciação entre instruir e ensinar, demonstrando, mais uma vez, a necessidade de que os mandados pedagógicos possuem da experiência real, ou mesmo, exemplificada pelo educador. Isto é, estes mandados precisam, em sua estrutura, de um conteúdo que seja possível vivenciar, fornecendo-lhe força e sentido, como evidenciam os relatos a seguir.

As estratégias que a gente tem usado para estar passando para o aluno essas questões, esses valores éticos e essas relações interpessoais são mais trazendo aquilo que eu vivencio lá no campo, que eu trago para eles (Depoimento 3).

Então, eu acho que o banho é importante, e você trabalhar com a questão não é só um banho. Primeiro você vai interagir com o paciente, você vai é aprender a ver o desnudo e respeitar, ver a questão da privacidade (Depoimento 4).

Os trechos dos depoimentos expressam claramente que, na experiência da comunicação do ensino de enfermagem, se firma um insólito pacto entre teoria (ciência) e prática (moral) capaz de promover avanços e negações de conhecimentos deterministas, ora por confirmarem-nos, respaldarem, seja porque são confirmados seja porque geram conflitos e incertezas quanto à sua aplicabilidade, possibilitando, com efeito, à pessoa transcendê-los, inová-los, ou modificá-los. Nesse movimento que se determina o futuro da ciência, da educação e do próprio olhar da pessoa sobre seu mundo a fim de torná-lo diferente, novo. ${ }^{18}$

É oportuno destacar que um processo educativo deve se tornar valioso para o estudante, considerando que sem isto não há o que ensinar ou aprender, posto que um ensino-aprendizagem eficaz surge do âmbito do real e decorre do saber acumulado. Logo, se o conteúdo ministrado não possuir correspondência em relação ao mundo vivido, este tenderá a ser inócuo. ${ }^{19}$ Por conseguinte, ao professor, em especial, ao de enfermagem, compete a tarefa de confrontar a informação e sua relação com a realidade, capacitar e permitir que o estudante apreenda, atribua ou reconstrua a relevância deste conteúdo.

O professor de enfermagem tende a acreditar que o estudante, por meio da vivência do cuidar, é lançado ao mundo dos valores e das relações interpessoais. Ele pode também se tornar o conselheiro fiel, o amigo da jornada que alerta para os perigos dela advindos, ao tempo que os instiga a apreciar a paisagem, ajudando a desnudar suas peculiaridades e belezas. Neste cenário é que se pode compreender e fornecer experiências ao estudante como indica a passagem abaixo.

Para entender [o paciente] como ser humano, eles têm que colocar os óculos. Que óculos são esses? É que vai dar a verdadeira visão do que é uma criança, do que vai ser este adulto [...]. Eu procuro repassar isso pra eles da maneira mais singular possível, mas eu creio que fica alguma coisa. Eu digo: "Vamos juntos que vale a pena, ao longo da disciplina" (Depoimento 1).

Partindo da visão do depoente, que utiliza da alegoria dos óculos para encorajar a percepção do mundo de relações, pode-se inferir que, para a enfermagem, é necessário para o estabelecimento de um canal educativo na relação professorestudante, que se valorize a experiência vivida, a fim de que informações sensíveis e racionais produzam eficácia, que haja o exercício da virtude da humildade, da abertura para o mundo, o outro e os valores da experiência vivida. Assim, as práticas educativas contribuem para esta apreensão e enraizamento de valores positivos. ${ }^{20}$

Contribuindo para esta reflexão sobre o ensino, assevera-se, em especial para a Enfermagem, que um processo educativo interligado com valores, pressupõe, como pilares, a descoberta, a incorporação e a efetivação de valores positivos pelo ser humano, destacando que uma pedagogia dos valores proporciona às pessoas, ou, pelo menos, direciona o olhar para conferir um sentido à vida, reconhecer e respeitar à dignidade de cada ser. ${ }^{21}$

Partindo deste enfoque, salienta-se que os esforços do professor destinam-se ao envolvimento do futuro profissional de enfermagem com o cuidar e com o aprender. A prática educativa não visa determinar medidas para um aprendizado, mas, sobretudo, cooperar com estas pessoas em sua busca por competências nesse mundo; com 
isso, no ato de questionar, a meta daquele que ensina mais do que a resposta é compreender. O interesse, o desejo e a vontade do estudante, eis em que consiste a recompensa do professor: perguntas, esforço, comentários, cooperação, a receptividade do estudante para o conteúdo ministrado. Ademais, "o aluno é infinitamente mais importante que a matéria". 22:223

A categoria em análise demonstra a preocupação dos entrevistados com a transmissão e valoração do conhecimento científico, entre outros, ressaltando que os denominados mandados pedagógicos possibilitam apenas discorrer que a educação em enfermagem reivindica para si um processo relacional ou comunicacional entre professor, estudante e paciente, visando despertar no outro sentimentos e valores que possam ajudar o estudante, não apenas na aquisição de informações, mas também a cada vez mais compreender o mundo. Trata-se de observar suas nuanças, de estabelecer competências e modificá-las, sem recorrer a um sistema rígido de ensino ou de uma visão racionalizante, mas seguindo a Lógica e a ordem do coração. Para alguns teóricos da educação, isto se denominaria emancipação do sujeito.

Neste entendimento, a capacidade de liderança do professor torna-se um requisito essencial para o êxito do ensino em enfermagem, que enquanto líder, influencia a vontade, exigindo um agir ou um comportamento que faz uso dos mandados pedagógicos a fim de despertar e fornecer ao estudante um sentido para determinadas impressões sobre o cuidar. Scheler afirma que "ser líder é agir, mostrar o caminho, dar à vida o rumo certo, ou errado no caso do mau líder". ${ }^{23: 36}$ Enquanto professor-líder, seus objetivos devem ser pautados no libertar e no estimular a autonomia do discente, a fim de que ele seja capaz de uma reflexão crítica sobre seu próprio agir.

\section{CONSIDERAÇÕES FINAIS}

O ensino de enfermagem deve ser um ato educativo comprometido com o outro, seus valores e suas relações, facilitador de um ethos pautado na reciprocidade e solidariedade, que possibilite a construção de uma conduta ética, cujo profissional, ao término de sua formação, seja capaz de reconhecer, em cada ação de cuidado, a necessidade e complexidade do ser humano.

Os discursos dos professores de enfermagem integrantes do estudo deixaram transparecer como estes comunicam os valores usando os mandados pedagógicos (conselhos, recomendações, deliberações morais, etc.), porém, estes não influenciam diretamente a disposição de ânimo dos estudantes. Este aspecto pode originar um modo de pensar e fazer em enfermagem que destoa na relação entre os atores, de maneira que o conteúdo ensinado não atende às expectativas do estudante, já que este raramente associa a teoria à prática, sendo também possível ocorrer o inverso, ou seja, tais orientações pedagógicas podem despertar o estudante para algo que ele ainda não havia atentado.

É oportuno mencionar que as práticas pedagógicas de enfermagem até a década de 1980, de acordo com a literatura, eram centradas em condutas que recordam os mandados pedagógicos e o simples cumprimento de regras, ou seja, posturas de disciplina, de obediência e de rígidos padrões éticos, geradoras de profissionais acríticos, moldados e voltados para cuidados técnicos no tratamento dos pacientes. Esta perspectiva é ainda adotada na atualidade, visto que um dos parâmetros estipulados pelo Ministério da Educação para reformulações no ensino de enfermagem é a resignificação da didática, abolindo técnicas de ensino tidas como tradicionais. ${ }^{24-25}$

Deste modo, uma proposta para vislumbrar a didática e o educar em enfermagem de uma forma diferente daquela, é compreender que o processo de ensino gera no professor a responsabilidade de iniciar o diálogo e a partilha destas vivências, ressaltando que os papéis de professor e estudante só existem de maneira hierarquizada no âmbito da institucionalização e da sociedade. Estes papéis sociais, na experiência vivida, se fazem igualmente presentes em cada interlocutor que, por sua natureza e capacidade, toca e se deixa tocar, sente e se deixa sentir, cuida e tem-se cuidado e, portanto, ensina e aprende. Ademais, sob este prisma, em que se insere o componente ético como um norteador do ensino e do próprio cuidado em enfermagem, é necessário que, pesquisadores, professores e enfermeiros se debrucem com maior afinco sobre o estudo da ética e dos deveres.

\section{REFERENCIAS}

1. Watson J, Foster R. The Attending Nurse Caring Model: integrating theory, evidence and advanced caringhealing therapeutics for transforming professional practice. J Clinic Nurs. 2003 Mai; 12(3):360-5.

2. Vidal M. Moral de atitudes: moral fundamental. São Paulo (SP): Santuário; 2000.

3. Frondizi R. Qué son los valores? Introducción a la axiología. México (MX): FCE; 2007. 
4. Scheler M. Ética: nuevo ensayo de fundamentación de un personalismo ético. Madrid (ES): Caparrós; 2001.

5. Hessen J. Filosofia dos valores. Coimbra (PT): Arménio Amado; 1967.

6. Scheler M. Ordo amoris. Madrid (ES): Caparrós; 1998.

7. Migallón SS. La persona humana y su formación em Max Scheler. Barañáin (ES): Ediciones Universidad de Navarra; 2006.

8. Puolimatka T. Max Scheler and the Idea of a well rounded education. Educ Philos Theory. 2008 Jun; 40(3):362-82.

9. Mounier E. O personalismo. São Paulo (SP): Martins Fontes; 1964.

10. Scheler M. Antologia. In.: Costa JS. Max Scheler: o personalismo ético. São Paulo (SP): Moderna; 1996.

11. Fitzpatrick JJ, Wallace M. Encyclopedia of nursing research. New York (US): Springer Publishing Company; 2006.

12. Moreira DA. O método fenomenológico na pesquisa. São Paulo (SP): Pioneira; 2004.

13. Costa SFGC, Valle ERM. Ser ético na pesquisa em enfermagem. João Pessoa (PB): Idéia; 2000.

14. Moustakas C. Phenomenological research methods. Califórnia (US): Sage; 1994.

15. Scheler M. La esencia de la filosofía y la condición moral del conocer filosófico. Buenos Aires (AR): Nova; 1958.

16. Perrenoud P. Novas competências para ensinar. Porto Alegre (RS): Artes Médicas; 2000.
17. Foucault M. Vigiar e punir. Petrópolis (RJ): Vozes; 2007.

18. Prado ML, Reibnitz KS, Gelbcke FL. Aprendendo a cuidar: a sensibilidade como elemento plasmático para formação da profissional crítico-criativa em enfermagem. Texto Contexto Enferm. 2006 Abr-Jun; 15(2):296-302.

19. Antunes C. Professores e professauros: reflexões sobre a aula e práticas pedagógicas diversas. Petrópolis (RJ): Vozes, 2007.

20. Puig JM. Aprender a viver. Arantes VA, organizador. Educação e valores: pontos e contrapontos. São Paulo (SP): Summus; 2007.

21. Kestenberg CCF, Reis MMSA, Motta WC, Caldas MF, Rodrigues DMC. Cuidando do estudante e ensinando relações de cuidado de enfermagem. Texto Contexto Enferm. 2006; 15(Esp):193-200.

22. Noddings N. O cuidador: uma abordagem feminina à ética e à educação moral. São Leopoldo (RS): Unisinos, 2003.

23. Scheler M. Modelos e líderes. Curitiba (PR): Champagnat; 1998.

24. Brasil VV, Alencar, CCP, Mucci I. Refletindo sobre a formação e desempenho do docente de enfermagem. Cogitare Enferm. 1996 Jul-Dez; 1(2):81-85.

25. Teixeira E, Vale EG, Fernandes JD, Sordi MRL, organizadores. $\mathrm{O}$ ensino de graduação em enfermagem no Brasil: o ontem, o hoje e o amanhã. Brasília (DF): INEP; 2006. 